\section{Classificação orientada a objeto de imagens de sensoriamento remoto em estudos epidemiológicos sobre leishmaniose visceral em área urbana}

\author{
Object-oriented remote sensing image \\ classification in epidemiological studies of \\ visceral leishmaniasis in urban areas
Clasificación orientada a objetos procedentes de imágenes satélite en los estudios epidemiológicos sobre leishmaniasis visceral en zonas urbanas

Andréa Sobral de Almeida 1 Guilherme Loureiro Werneck 1,2 Ana Paula da Costa Resendes 3

\footnotetext{
${ }^{1}$ Instituto de Medicina Social, Universidade do Estado do Rio de Janeiro, Rio de Janeiro, Brasil. 2 Instituto de Estudos em Saúde Coletiva, Universidade Federal do Rio de Janeiro, Rio de Janeiro, Brasil. 3 Programa Municipal de Hanseníase, Secretaria de Vigilância em Saúde de Nova Iguaçu, Nova Iguaçu, Brasil.

Correspondência A. S. Almeida Instituto de Medicina Social, Universidade do Estado do Rio de Janeiro.

Rua São Francisco Xavier 524, 7o andar, Bloco D, Rio de Janeiro, RJ 20550-900, Brasil.

asasobral@gmail.com
}

\begin{abstract}
This study explored the use of object-oriented classification of remote sensing imagery in epidemiological studies of visceral leishmaniasis (VL) in urban areas. To obtain temperature and environmental information, an object-oriented classification approach was applied to Landsat 5 TM scenes from the city of Teresina, Piaui State, Brazil. For 1993-1996, VL incidence rates correlated positively with census tracts covered by dense vegetation, grass/pasture, and bare soil and negatively with areas covered by water and densely populated areas. In 2001-2006, positive correlations were found with dense vegetation, grass/pasture, bare soil, and densely populated areas and negative correlations with occupied urban areas with some vegetation. Land surface temperature correlated negatively with VL incidence in both periods. Object-oriented classification can be useful to characterize landscape features associated with VL in urban areas and to help identify risk areas in order to prioritize interventions.
\end{abstract}

Remote Sensing Technology; Satellite Imagery; Visceral Leishmaniasis

\section{Resumo}

Neste estudo, explorou-se o uso da classificação orientada a objeto de imagens de sensoriamento remoto em estudos epidemiológicos sobre leishmaniose visceral (LV) em áreas urbanas. A classificação orientada a objeto foi aplicada a cenas Landsat 5 TM da cidade de Teresina, Piauí, Brasil, para obtenção de informações ambientais e temperatura. Para o período de 1993-1996, a taxa de incidência de LV nos setores censitários da cidade foi positivamente correlacionada com a área do setor censitário coberta por vegetação densa, rasteira e solo exposto e negativamente com a área coberta por água e áreas densamente ocupadas. No período de 2001-2006, foram encontradas correlações positivas com vegetação densa, rasteira, solo exposto $e$ áreas densamente ocupadas e negativas com áreas urbanas com alguma vegetação. A temperatura da superfície terrestre foi negativamente associada à incidência de LV nos dois períodos. A classificação orientada a objeto pode ser útil para caracterizar paisagens associadas à ocorrência da LV em áreas urbanas e delimitar áreas de risco para definição de prioridades na implementação de intervenções.

Tecnologia de Sensoriamento Remoto; Imagens de Satélites; Leishmaniose Visceral 


\section{Introdução}

No Brasil, o processo de urbanização acelerado, associado a modificações ambientais, tem provocado sérios impactos no perfil de adoecimento da população, particularmente no que diz respeito às doenças transmitidas por vetores 1,2 . Paralelamente, tem-se observado o aumento do interesse em estudos acerca das consequências do crescimento urbano na saúde da população usando imagens de sensoriamento remoto 3 . Nesse contexto, o sensoriamento remoto tem sido considerado uma importante ferramenta nos estudos de doenças relacionadas às condições ambientais 3,4 , como a leishmaniose visceral (LV).

Transformações ambientais associadas aos movimentos migratórios e ao próprio processo de urbanização têm sido implicadas na introdução e manutenção da LV em grandes cidades brasileiras. Isso se dá porque o processo desordenado de ocupação urbana resulta em condições precárias de vida e destruição ambiental, promovendo condições favoráveis para a reprodução do principal vetor da LV no Brasil, o flebotomíneo Lutzomyia longipalpis, que se adapta facilmente às condições peridomésticas de áreas urbanas empobrecidas 5 .

A introdução da LV nas cidades configura um cenário epidemiológico diverso daquele previamente conhecido, requerendo uma nova racionalidade para os sistemas de vigilância e de controle. Nesse sentido, a utilização do sensoriamento remoto para caracterizar o uso e a cobertura do solo pode ser uma ferramenta auxiliar na demarcação e predição de áreas de alto risco para a doença, o que poderia ser útil para informar como e onde as estratégias de intervenção podem ser mais eficientemente implementadas 6 .

De um modo geral, a produção de mapas de uso e cobertura do solo a partir de informações de imagens de satélite é realizada por meio de interpretação visual ou por procedimentos de classificação automática. A interpretação visual é apoiada no conhecimento prévio do especialista sobre a região e tem a vantagem de fazer uso de informações complexas como cor, forma e textura para a identificação de padrões na imagem. Embora possa fornecer resultados satisfatórios em diversas circunstâncias, o uso de técnicas automáticas tem sido considerado uma opção mais viável para a classificação do solo urbano em larga escala, já que a interpretação visual é um procedimento mais demorado e dispendioso 7 .

Os classificadores automáticos podem ser supervisionados ou não supervisionados, na dependência do grau de interação do investigador, isto é, procedimentos supervisionados geralmente exigem informações a priori sobre a área a ser mapeada. Esse conhecimento prévio sobre a área de estudo é incorporado no processo a partir de um conjunto de regras que farão parte do sistema de classificação.

Tradicionalmente, para imagens de média resolução, os procedimentos de classificação são orientados a pixel (classificação pixel a pi$x e l)$ ou a agrupamentos de pixels (segmentos), ambos utilizando essencialmente informações espectrais. Os processos automatizados de classificação orientados a objetos também baseiam sua análise em pequenos segmentos da imagem ${ }^{8}$, mas utilizam, além dos dados espectrais, informações de forma, textura e contextuais/ topológicas 9 , o que pode trazer benefícios na construção de mapas de uso e cobertura do solo em ambientes heterogêneos e complexos como os encontrados em áreas urbanizadas. Assim, a classificação orientada a objetos teria a vantagem de abordar o espaço de forma mais integrada, identificando contextos mais similares em termos de ocupação do solo.

Diante disso, o objetivo deste estudo é avaliar a aplicabilidade da estratégia de classificação orientada a objeto na busca de possíveis indicadores de cobertura do solo relacionados com a ocorrência da LV em meio urbano em dois períodos do tempo.

\section{Métodos}

\section{Área de estudo}

Teresina, capital do Piauí, Brasil, está localizada em zona de transição de matas de babaçuais e a mata pré-atlântica na confluência dos rios Parnaíba e Poti, ao lado do município maranhense de Timon, localizando-se a 505' de latitude Sul e a 42048' de longitude Oeste. O clima é tropical subúmido quente, com temperaturas variando de $22^{\circ} \mathrm{C}$ a $40^{\circ} \mathrm{C}$. A vegetação é representada por uma cobertura arbustiva densa de médio porte, sendo o cerrado e o cerradão as formas mais generalizadas, com babaçuais e carnaubais integrandose a essa paisagem, coexistindo nas periferias da cidade regiões de pastagem e floresta tropical.

Em 2010, a cidade apresentava uma população de 814.230 habitantes e uma área territorial de $1.392 \mathrm{~km}^{2}$, com uma densidade populacional de 585 habitantes $/ \mathrm{km}^{2}$, sendo que a área urbana do município corresponde a cerca de $20 \%$ de sua área total.

Em 1980, Teresina foi o local de ocorrência da primeira epidemia urbana de LV no Brasil 10. A incidência caiu após 1985, mas uma nova epidemia com mais de 1.200 casos ocorreu entre 1993 e 1995. Entre 1996 e 1998, a doença permaneceu 
ocorrendo de forma endêmica em Teresina com cerca de 20-40 casos anuais. A partir de 1998, a incidência da doença se estabilizou em torno de 20 casos por 100 mil habitantes.

\section{Desenho de estudo}

Estudo ecológico cujas unidades espaciais de análise se basearam nos setores censitários do Censo Demográfico de 1991 e 2000, para os períodos de 1993-1996 e de 2001-2006, respectivamente. Para o período de 1993-1996, os 494 setores censitários de 1991 foram agregados em 430 unidades de análise, de forma que, pelo menos, um caso de LV fosse esperado ocorrer em cada. Em 2000, dos 654 setores censitários, foram utilizados 653, pois um desses, localizado na região sul, teve que ser excluído porque não possuía informação populacional.

\section{Dados}

Os casos de LV considerados para o estudo foram aqueles disponíveis no Sistema de Informação de Agravos de Notificação (SINAN), ocorridos na área urbana de Teresina, nos períodos de 19931996 e de 2001-2006. Esses foram georreferenciados, em nível de domicílio, utilizando-se um receptor de sistema de posicionamento global (GPS), com o Sistema de Projeção Universal Transversa - UTM e, posteriormente, alocados aos setores censitários. Para o período de 19931996, foram georreferenciados 1.075 casos $(93 \%)$ dos 1.155 notificados, e, para o período de 2001 2006, foram georreferenciados 670 (89\%) casos dos 756 notificados. A cobertura de georreferenciamento variou de $82,1 \%$ (2006) a 98,9\% (1993).

Utilizando-se os dados populacionais dos censos demográficos de 1991 e 2000 e da contagem populacional de 2007 , foram realizadas estimativas populacionais anuais para cada setor censitário por interpolação, por meio de uma equação de crescimento geométrico com componente anual 11 . O cálculo da taxa de incidência anual média da LV foi feito dividindo-se o número total de casos novos registrados nos períodos de 1993-1996 e de 2001-2006 pela soma das populações estimadas para cada um dos anos nos períodos estudados, respectivamente.

Para captação de informações ambientais, foram utilizadas as cenas do Landsat 5 Thematic Mapper (TM) de agosto de 1990 e de junho de 2003, órbita 219, ponto 64, projeção UTM, disponíveis na página de Internet http://www.lan dcover.org/ (Global Land Cover Facility, National Aeronautics and Space Administration, Estados Unidos).

\section{Processamento de imagens}

A classificação da imagem teve como objetivo extrair as seguintes características referentes à cobertura do solo: água, ocupação urbana densa, ocupação urbana em locais com alguma vegetação, solo exposto, vegetação densa e vegetação rasteira. Para a obtenção das características de cobertura do solo, foi realizada uma classificação orientada a objetos envolvendo cinco etapas: caracterização das classes, segmentação da imagem, elaboração da rede semântica, classificação e avaliação dos resultados.

Foi elaborada uma composição falsa cor nas imagens de 1990 e de 2003, com a combinação das bandas 3, 4 e 5, respectivamente, nas cores azul, verde e vermelho. Essa composição apresenta uma boa discriminação visual dos alvos, possibilitando a identificação dos padrões de uso do solo. Nessa composição, os corpos d'água apresentam-se em tons azulados; as áreas de cobertura vegetal, em tons esverdeados; e as áreas de solo exposto e urbanizadas, em tons avermelhados. No entanto, para a classificação das imagens, foram utilizadas apenas as bandas 3 (vermelho) e 4 (infravermelho próximo), por apresentarem maiores diferenças espectrais e para fins de cálculo do Índice de Vegetação por Diferença Normalizada (Normalized Difference Vegetation Index - NDVI) ${ }^{3}$.

O procedimento de classificação das imagens foi realizado no aplicativo Definiens 7.0 (Definiens, Munique, Alemanha) e incluiu basicamente dois passos: segmentação multirresolução e classificação por algoritmos com lógica fuzzy e booleana 9 .

A classificação orientada a objetos se realiza sobre segmentos da imagem (objetos). Os objetos com características comuns são agrupados em classes, e as classes são organizadas em forma de rede hierárquica e semântica. A análise de imagens orientada a objetos emprega informações espaciais em seu processamento e, por isso, tem se mostrado mais eficiente na aplicação em áreas urbanas 12 .

Inicialmente, foi realizada uma interpretação visual da imagem para definir quais classes temáticas seriam importantes na caracterização do território em termos de suas relações com a transmissão da LV. Após a definição dessas classes, as imagens de satélite foram segmentadas por meio do algoritmo multirresolução, no qual foram criados objetos em diferentes escalas, de acordo com critérios de forma, cor e homogeneidade. Além disso, a malha de vias de Teresina foi utilizada na segmentação para melhor definição do contexto urbano. Como o resultado dessa fase tem repercussão nas demais, foram feitos vários testes até se obter uma definição apropriada dos 
valores dos parâmetros a serem utilizados na segmentação. Por meio de algoritmo implementado no aplicativo Definiens Developer, atributos de forma (compacidade e suavidade) e cor são utilizados para caracterizar os diferentes segmentos 13. Por último, o tamanho dos objetos da segmentação é determinado pelo valor do fator de escala, de modo que esse corresponda a uma Unidade Mínima de Mapeamento (Minimal Mapping Unit-MMU) 14.

Foi elaborado um modelo preliminar de conhecimento, após a identificação das classes (Figura 1). A classe Água foi separada, primeiramente, pelo algoritmo Classification, no qual foram utilizadas as características brilho e média da banda 4 . Os demais objetos da cena não classificados foram definidos como a classe Não água. Para separar a classe Água, utilizou-se também a relação de bordas com objetos vizinhos (Rel. border to) por meio do algoritmo Assign class, que trata da relação de classes entre segmentos contidos no mesmo nível na hierarquia do segmento. Esse parâmetro foi utilizado porque algumas áreas do rio Parnaíba não foram classificadas adequadamente por apresentarem assoreamento.

Posteriormente, todos os objetos da classe Não água foram separados em duas novas classes: Vegetação e Área antropizada. Para separar a classe Vegetação, foi utilizado a razão das bandas 4 e 3. A classe Vegetação deu origem às classes Vegetação densa e Vegetação rasteira, discriminadas por meio do NDVI, que permitiu minimizar a confusão espectral decorrente de efeitos de sombreamento. O NDVI é calculado mediante a razão entre a diferença das medidas de reflectância espectral adquiridas nas bandas do infravermelho próximo e do vermelho e a soma delas 3 .

Já a classe Área antropizada deu origem às classes Urbana densa (ocupação urbana densa), Urbana verde (ocupação urbana em locais com alguma vegetação) e Solo exposto. Essas foram separadas por diferentes limiares da banda 3. A banda 3 foi escolhida por apresentar maior sensibilidade para diferenciar áreas cobertas por vegetação das áreas de solo exposto, estradas e áreas urbanas 15. Da mesma forma que na classe Água, o parâmetro de relação de bordas com objetos vizinhos foi utilizado para melhor distinguir a classe Solo exposto.

Essas regras de decisão serviram de base para a elaboração da rede semântica. Na rede semântica, as classes herdam atributos e comportamentos das superclasses (Água, Não água, Área antropizada e Vegetação) que as contém.

As regras de decisão com os parâmetros utilizados para segmentar e classificar a imagem de 1990 foram aplicadas à imagem de 2003, com pequenos ajustes no limiar dos parâmetros, por exemplo, o brilho, a geometria de um objeto e as características de textura e de relacionamento entre classes. Esses ajustes foram realizados em função das variações na resposta espectral e/ou contextual que os objetos da cena de 2003 apresentaram em relação aos definidos preliminarmente na cena de 1990.

Como todo processo de classificação está sujeito a erros, foi realizado um procedimento para avaliação quantitativa da acurácia do mapeamento ${ }^{16}$. Assim, para esta avaliação, foram coletados cerca de 12 pontos de referência sobre a área estudada para cada classe analisada e comparados com a "verdade" terrestre, definida com o auxílio do Google Earth (http://www.goo gle.com/earth). Algumas dificuldades foram encontradas nesse processo devido à diferença de resolução espacial e de datas entre as imagens, no entanto, não se constituíram como limitantes absolutos para a análise da acurácia.

Dessa forma, foram calculadas as matrizes de confusão ou de erros, que mostram o percentual de objetos que foram mapeados de forma correta ou não (erros de inclusão ou exclusão) para ambas as imagens. Esses erros são expressos em medidas de acurácia global, acurácia do produtor e do usuário ${ }^{17}$. A acurácia global corresponde à proporção do total de amostras corretamente classificadas, enquanto as acurácias do usuário e do produtor são calculadas para cada classe. Assim, a acurácia do produtor corresponde à proporção de amostras de uma dada classe que foram corretamente classificadas, enquanto a acurácia do usuário indica a probabilidade de que um objeto classificado na imagem de fato represente aquela categoria no campo. Na terminologia epidemiológica, as acurácias do produtor e do usuário têm analogia, respectivamente, com a sensibilidade (proporção de objetos de uma certa classe corretamente classificados) e valor preditivo positivo (proporção de objetos alocados a uma certa classe que de fato pertencem àquela classe).

O coeficiente kappa foi utilizado para mensurar a concordância das classificações realizadas com amostras teste com base nas coordenadas capturadas em cada imagem no Google Earth. Esse coeficiente mensura o grau de concordância corrigida pela concordância esperada pelo acaso 18 . Foram utilizados, para a interpretação dos valores de kappa, os critérios de Landis \& Koch: concordância pobre $(<0,00)$; discreta $(0,00-0,20)$; razoável $(0,21-0,40)$; moderada $(0,41-0,60)$; substancial $(0,61-0,80)$ e quase perfeita $(0,81-1,00) 18$.

Os indicadores ambientais para ambos os períodos analisados foram construídos por meio do cálculo da proporção de cada classe temática 


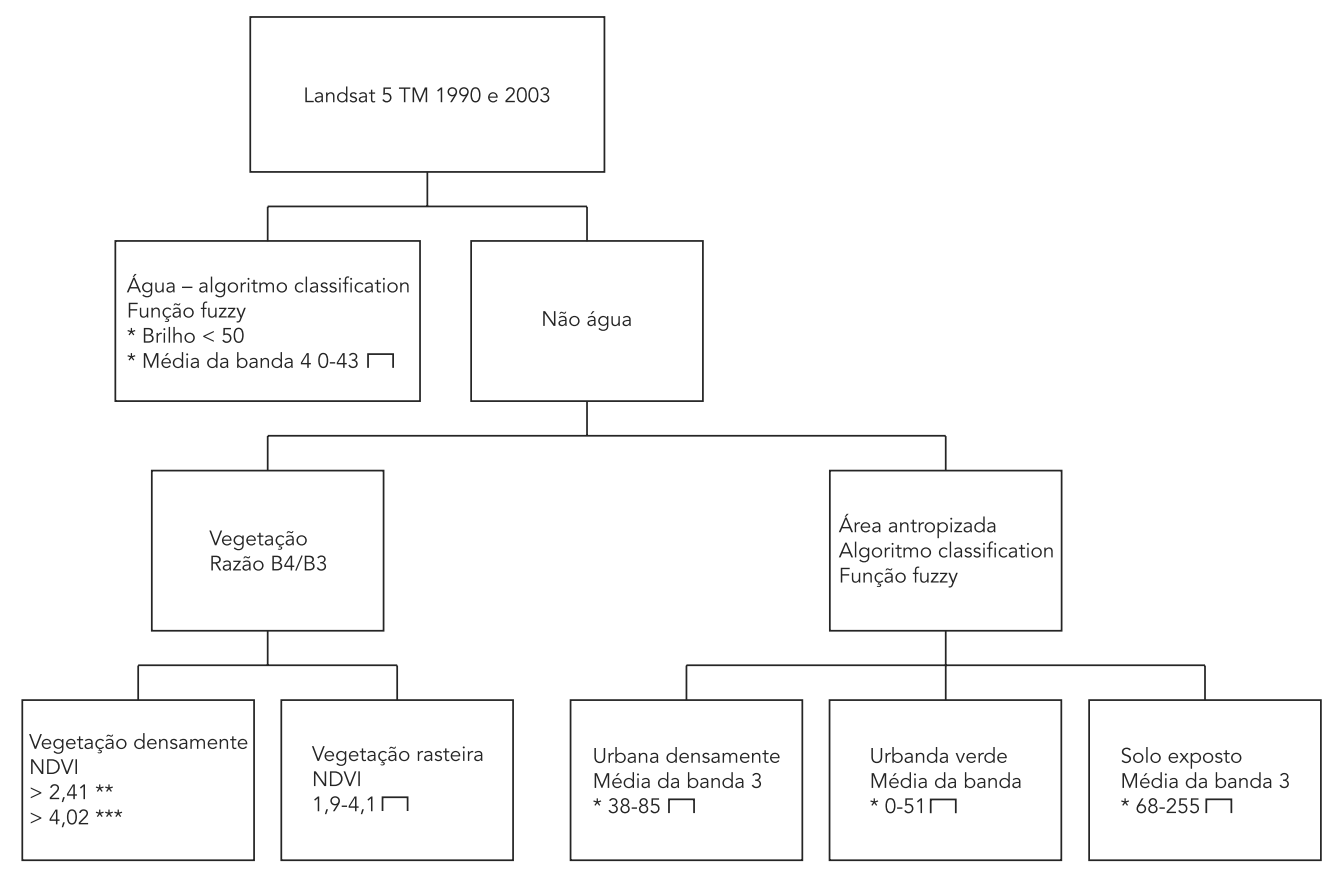

* Os limiares em cada classe representam a amplitude utilizada para a classificação das duas imagens de Landsat STM (1990 e 2003);

** Valores usados na cena 1990;

*** Valores usados na cena 2003.

definida para cada setor censitário. Esse cálculo foi feito utilizando-se o programa LEGAL no SPRING (Instituto Nacional de Pesquisas Espaciais - INPE).

Para avaliação do crescimento urbano, foi realizado o mapeamento das classes área Urbana densa, Urbana verde e Vegetação densa extraídas da classificação das cenas de Landsat 5 TM de 1990 e 2003. Dessa forma, foram geradas, a partir dos mapeamentos obtidos das imagens, duas figuras identificando as áreas de expansão entre 1990 e 2003, buscando, por meio dessa representação espacial, facilitar a análise da expansão urbana de Teresina.

\section{Campo térmico da superfície do solo}

Para a identificação da temperatura da superfície terrestre, foram utilizadas as bandas termais (banda 6) de cada imagem (1990 e 2003). As imagens do campo térmico da área urbana de Teresina foram transformadas em imagens termais pe- lo modelo de regressão quadrática desenvolvido por Malaret et al. ${ }^{19}$ :

$\mathrm{T}=209.831+0.834 \mathrm{DN}-0.00133 \mathrm{DN}^{2}$

em que: $\mathrm{T}=$ temperatura aparente em Kelvin $(\mathrm{K})$, $\mathrm{DN}=$ digital number ou número digital de cada pixel.

Esse método permite a geração de imagens da temperatura da superfície em Kelvin a partir das medidas de temperatura radiante emitida pela superfície terrestre, captada pelo sensor do satélite. A obtenção da temperatura da superfície é feita mediante a conversão do número digital (DN) de cada pixel da imagem na banda termal em temperatura aparente da superfície do solo cujas medidas se obtêm por meio do sensor infravermelho termal. Posteriormente, as temperaturas foram convertidas em graus Celsius $\left({ }^{\circ} \mathrm{C}\right)$, com a subtração do valor da temperatura do ponto de congelamento da água ao nível do mar, ou seja, $273,15 \mathrm{~K}$, fornecendo, assim, a temperatura da superfície da cidade de Teresina. 


\section{Análise estatística}

As incidências anuais médias da LV nos períodos de 1993-1996 e de 2001-2006 foram correlacionadas com os indicadores ambientais obtidos pelo processamento das imagens de satélite e também com o campo térmico da superfície do solo de Teresina, por meio do coeficiente de correlação de Spearman, usando o aplicativo Splus (Mathsoft Inc., Seattle, Estados Unidos). A apreciação dessas correlações tem o intuito de contribuir para a avaliação da adequação da classificação na medida em que se espera um certo comportamento dessas correlações de forma a corroborar o conhecimento estabelecido sobre a relação entre aspectos paisagísticos e os padrões de ocorrência da doença. Nesse sentido, o encontro de associações previstas ou em consonância com resultados anteriormente descritos reforçaria a validade do processo de classificação 20 . Dessa forma, com o conhecimento a priori do ciclo de transmissão da LV, espera-se, por exemplo, encontrar correlações positivas com áreas de maior cobertura vegetal e negativas com áreas mais urbanizadas.

\section{Resultados}

A Figura 2 mostra o resultado da classificação orientada a objeto nos dois anos analisados (1990 e 2003).

A Tabela 1 mostra as matrizes de erros e os índices de acurácia e confiabilidade da classificação das imagens de 1990 e 2003. Os resultados indicam bom desempenho da classificação na medida em que há poucas situações de classificação fora da diagonal da matriz de erros. Os índices de acurácia e confiabilidade foram altos, maiores que $90 \%$, indicando que a separação entre as classes temáticas foi altamente satisfatória para as imagens utilizadas na análise (Tabelas $1 \mathrm{e}$ 2). Cabe ressaltar que as classes Água, Vegetação densa e Vegetação rasteira, na imagem de 1990 (Tabela 1), e as classes Vegetação densa, Urbana densa e Solo exposto, na imagem de 2003, tiveram $100 \%$ de acerto na classificação. As acurácias do usuário e do produtor foram satisfatórias em ambas as imagens classificadas.

A Figura 3 mostra a expansão urbana em direção à periferia da cidade em 2003 (Figura 3a) e a expansão das áreas urbanas com alguma vegetação (classe Urbana verde) (Figura 3b). Em 1990, eram mais de $39 \mathrm{~km}^{2}$ de áreas urbanizadas com alguma vegetação, enquanto que, em 2003, há um pouco mais de $35 \mathrm{~km}^{2}$, ou seja, uma redução de quase $4 \mathrm{~km}^{2}$. Já para o indicador de área Urbana densa, nota-se uma expansão do território de aproximadamente $38 \mathrm{~km}^{2}$. Esse cenário pode ser observado mais claramente comparando a ocupação das classes Urbana verde e Urbana densa nos dois períodos analisados (1990 e 2003) (Figuras 3c e 3d). Na Figura 4, observa-se um padrão de expansão do território urbano para áreas cobertas por vegetação densa em 1990 e para áreas urbanizadas com alguma vegetação.

A Tabela 2 apresenta as matrizes de correlação para os períodos de 1993-1996 e de 20012006. Verificou-se correlação positiva da incidência da LV em 1993-1996 com a área do setor censitário coberta por vegetação densa, vegetação rasteira e solo exposto (todos os valores de $\mathrm{p}<$ 0,01) e negativa com a área coberta por água e áreas densamente ocupadas ( $\mathrm{p}<0,05$ para ambos). No período subsequente (2001-2006), foram encontradas correlações positivas para a vegetação densa, vegetação rasteira, solo exposto e áreas densamente ocupadas (todos os valores de $\mathrm{p}<0,01)$ e correlação negativa com áreas urbanas com alguma vegetação $(\mathrm{p}<0,01)$. A temperatura média da superfície terrestre apresentou correlação negativa com a incidência de LV nos dois períodos analisados.

Correlações estatisticamente significantes $(\mathrm{p}<0,01)$ entre vários indicadores ambientais também podem ser observadas. Para a imagem de 1990, observa-se, por exemplo, que há correlação positiva entre as áreas dos setores censitários cobertas por Vegetação rasteira e Vegetação densa. Já a área dos setores com proporção de Urbana verde apresenta correlação inversa com a cobertura de Vegetação densa, Vegetação rasteira e Urbana densa. Também, a área coberta por Solo exposto apresenta correlação positiva com Vegetação rasteira e Vegetação densa e inversa com a proporção de área Urbana densa.

Observa-se ainda um número maior de correlações estatisticamente significantes $(\mathrm{p}<0,01)$ entre os indicadores ambientais obtidos da imagem de 2003. Destacam-se as correlações positivas entre a área coberta por Água, Vegetação densa e Vegetação rasteira. As áreas com proporção Urbana densa apresentam correlação positiva com Vegetação densa e inversa com Água. Já a Urbana verde apresenta correlações inversas com as proporções de Água, Vegetação densa, Vegetação rasteira e Urbana densa. Por fim, setores com proporção de Solo exposto apresentam correlação positiva com Vegetação densa e Vegetação rasteira.

\section{Discussão}

A possibilidade de incorporar uma pluralidade de informações como forma do objeto (área 


\section{Figura 2}

Mapa temático da cobertura do solo do Município de Teresina, Piauí, Brasil, derivado do processamento das imagens Landsat 5 TM, referentes aos anos de 1990 e 2003.

2a) 1990

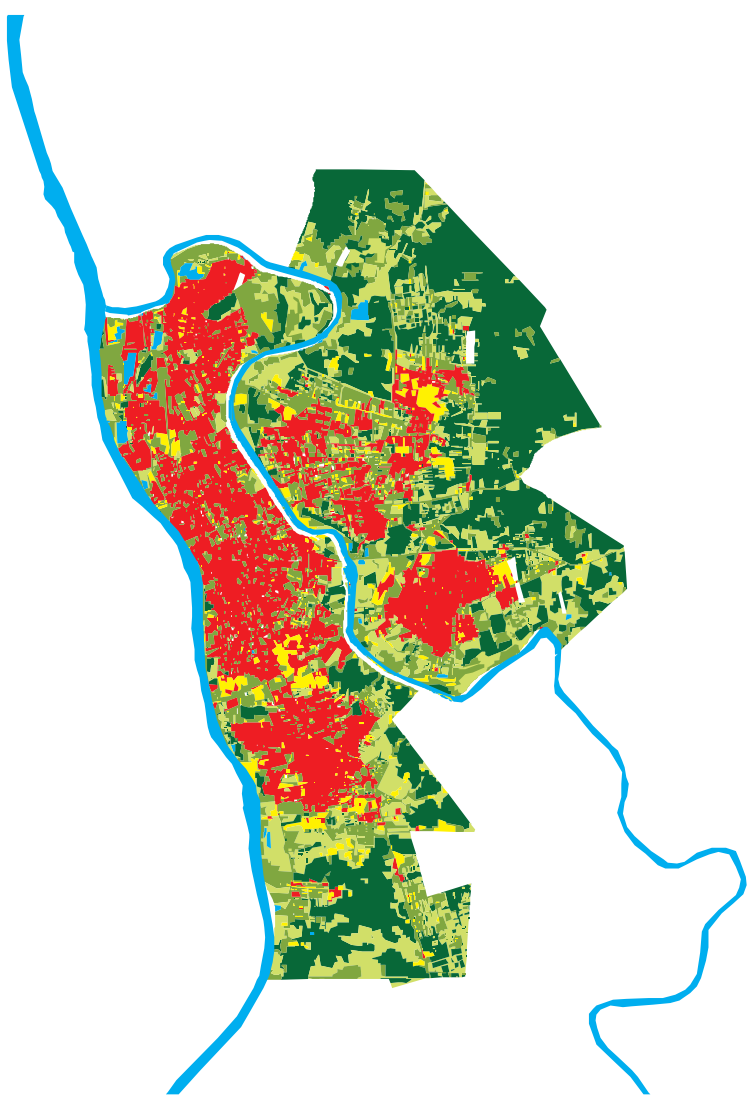

2b) 2003

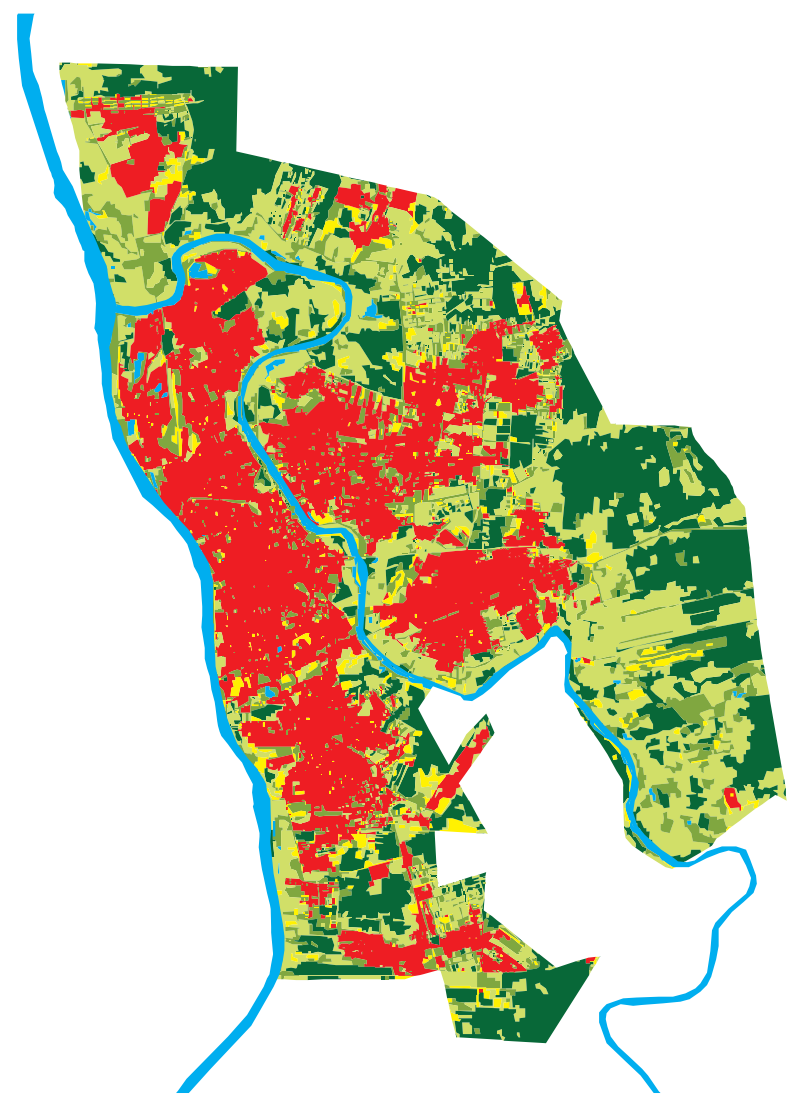

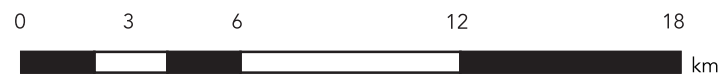

Projeção Universal Transversa de Mercator

Datum horizontal: South American 1969

ESCALA: 1:266.756

Classificação da cobertura do solo de Teresina

$\square$ Solo exposto

Urbana densa

Solo exposto

Vegetação densa

Vegetação rasteira

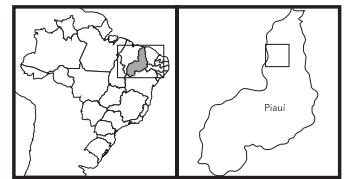

Água 
Resultado da avaliação da classificação da imagem Landsat 5 TM de 1990 e 2003. Município de Teresina, Piauí, Brasil.

\begin{tabular}{|c|c|c|c|c|c|c|c|c|}
\hline Classes/Amostras & Água & $\begin{array}{c}\text { Vegetação } \\
\text { densa }\end{array}$ & $\begin{array}{c}\text { Vegetação } \\
\text { rasteira }\end{array}$ & $\begin{array}{l}\text { Urbana } \\
\text { densa }\end{array}$ & $\begin{array}{l}\text { Urbana } \\
\text { verde }\end{array}$ & $\begin{array}{c}\text { Solo } \\
\text { exposto }\end{array}$ & $\begin{array}{c}\text { Não } \\
\text { classificada }\end{array}$ & Soma \\
\hline \multicolumn{9}{|l|}{ Matriz de erros (1990) } \\
\hline Água & 17 & 0 & 0 & 0 & 0 & 0 & 0 & 17 \\
\hline Vegetação densa & 0 & 29 & 0 & 0 & 0 & 0 & 0 & 29 \\
\hline Vegetação rasteira & 0 & 0 & 23 & 0 & 0 & 0 & 0 & 23 \\
\hline Urbana densa & 0 & 0 & 0 & 44 & 1 & 2 & 0 & 47 \\
\hline Urbana verde & 0 & 0 & 0 & 0 & 23 & 0 & 0 & 23 \\
\hline Solo exposto & 0 & 0 & 0 & 2 & 0 & 26 & 0 & 28 \\
\hline Não classificada & 0 & 0 & 0 & 0 & 0 & 0 & 0 & 0 \\
\hline Soma & 17 & 29 & 23 & 46 & 24 & 28 & 0 & 167 \\
\hline \multicolumn{9}{|c|}{ Índices de acurácia e confiabilidade } \\
\hline Produtor & 1,00 & 1,00 & 1,00 & 0,96 & 0,96 & 0,93 & & \\
\hline Usuário & 1,00 & 1,00 & 1,00 & 0,94 & 1,00 & 0,93 & & \\
\hline Kappa por classe & 1,00 & 1,00 & 1,00 & 0,94 & 0,95 & 0,91 & & \\
\hline Acurácia global & 0,97 & & & & & & & \\
\hline Kappa & 0,96 & & & & & & & \\
\hline \multicolumn{9}{|l|}{ Matriz de erros (2003) } \\
\hline Água & 17 & 0 & 0 & 0 & 0 & 0 & 0 & 17 \\
\hline Vegetação densa & 0 & 29 & 2 & 0 & 0 & 0 & 0 & 31 \\
\hline Vegetação rasteira & 1 & 0 & 24 & 0 & 0 & 0 & 0 & 25 \\
\hline Urbana densa & 0 & 0 & 0 & 38 & 1 & 0 & 0 & 39 \\
\hline Urbana verde & 0 & 0 & 0 & 0 & 30 & 0 & 0 & 30 \\
\hline Solo exposto & 0 & 0 & 0 & 0 & 0 & 33 & 0 & 33 \\
\hline Não classificada & 0 & 0 & 0 & 0 & 0 & 0 & 0 & 0 \\
\hline Soma & 18 & 29 & 2 & 38 & 31 & 33 & 0 & 175 \\
\hline \multicolumn{9}{|c|}{ Índices de acurácia e confiabilidade } \\
\hline Produtor & 0,94 & 1,00 & 0,92 & 1,00 & 0,97 & 1,00 & & \\
\hline Usuário & 1,00 & 0,93 & 0,96 & 0,97 & 1,00 & 1,00 & & \\
\hline Kappa por classe & 0,94 & 1,00 & 0,91 & 1,00 & 0,96 & 1,00 & & \\
\hline Acurácia global & 0,98 & & & & & & & \\
\hline Kappa & 0,97 & & & & & & & \\
\hline
\end{tabular}

densidade, altura, dimensão etc.), textura e relações entre objetos vizinhos (informações contextuais) é uma das potenciais vantagens da classificação orientada a objetos para uso no ambiente urbano quando comparada aos métodos de classificação de imagens de satélite tradicionais, que se baseiam fundamentalmente em informações espectrais 8,21.

Assim, como, no contexto territorial urbano, muitas das feições (ruas, edificações residenciais ou comerciais/industriais e áreas verdes) podem possuir respostas espectrais similares, em função da composição de cada material, a utilização da abordagem orientada a objeto traz novos elementos para o desafio de classificar a grande diversidade do uso do solo em áreas urbanas.
Outra vantagem dessa abordagem seria a possibilidade de caracterizar cada objeto não somente em suas propriedades espectrais, mas também considerando suas características espaciais, pelas regras fuzzy. Isso torna possível a reprodutibilidade do método, ainda que esse precise ser adequado, devido às especificidades da paisagem e dos dados de sensoriamento remoto utilizados em cada caso 22 . Além disso, os diferentes graus de pertinência, disponíveis na lógica fuzzy, permitem um refinamento da classificação. Pode ser considerada também como ponto positivo da classificação orientada a objeto a utilização de uma rede semântica, constituída por uma estrutura hierárquica/topológica de classes associadas aos objetos da imagem 23 . 
Figura 3

Mapas temáticos com as classes "Urbana densa" e "Urbana verde" referentes aos anos de 1990 e 2003. Teresina, Piauí, Brasil.

3a)

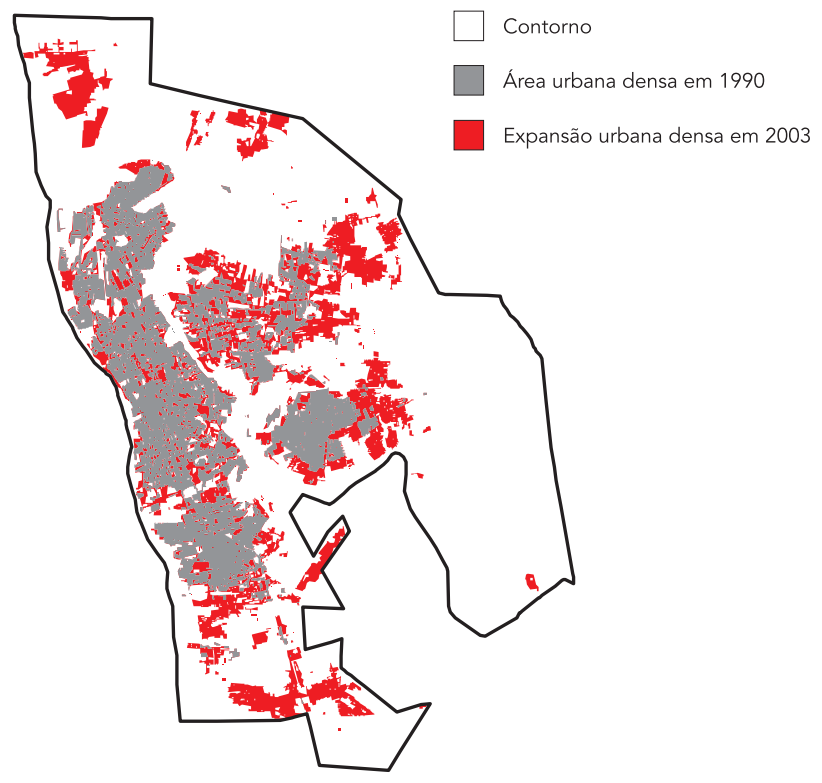

3c)

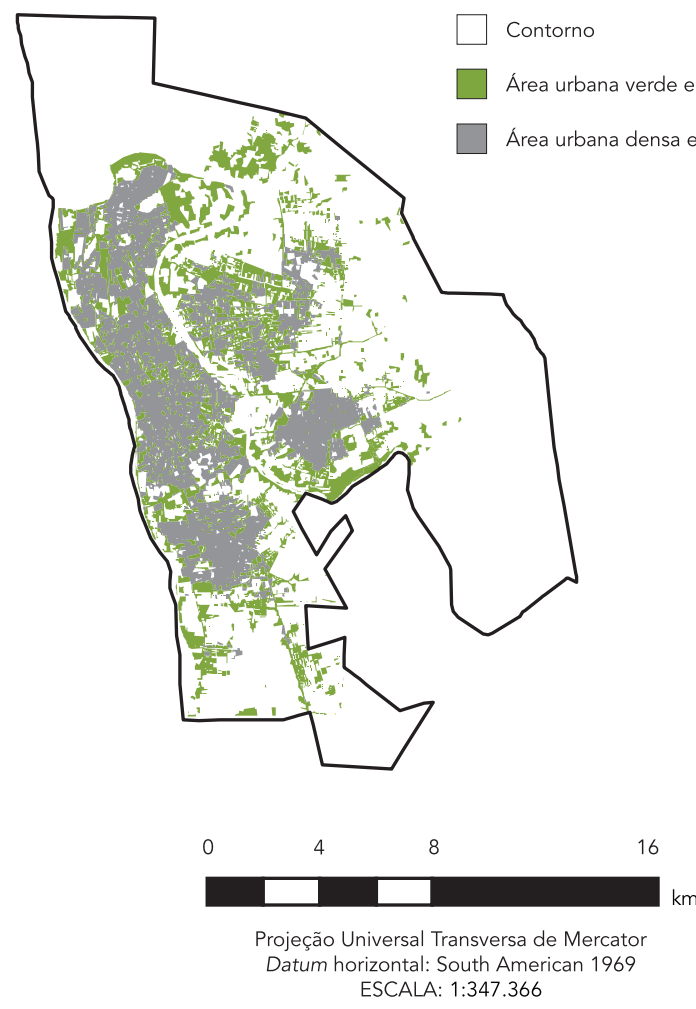

3b)

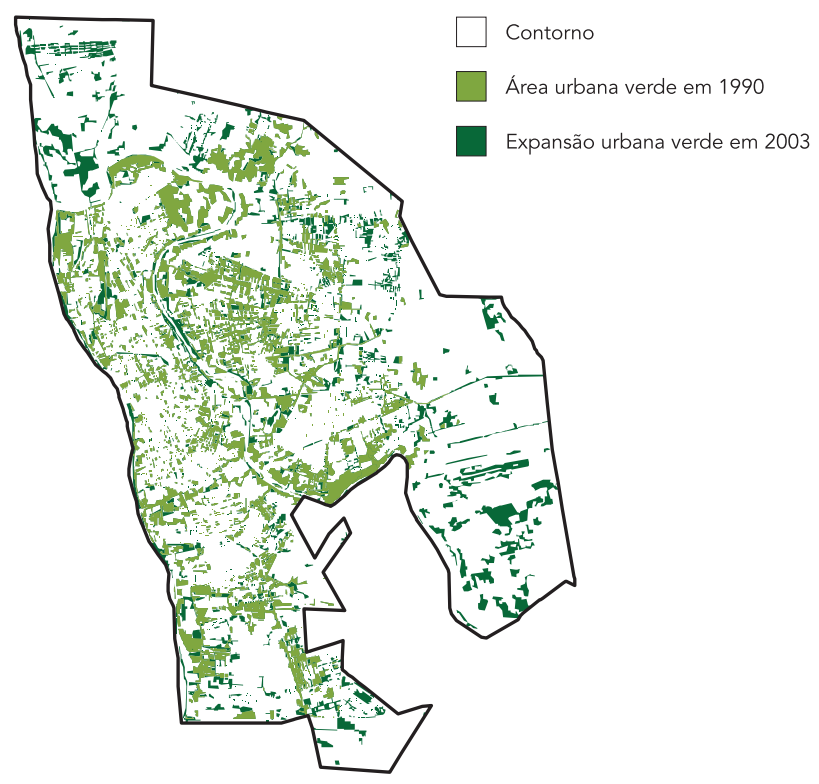

3d)
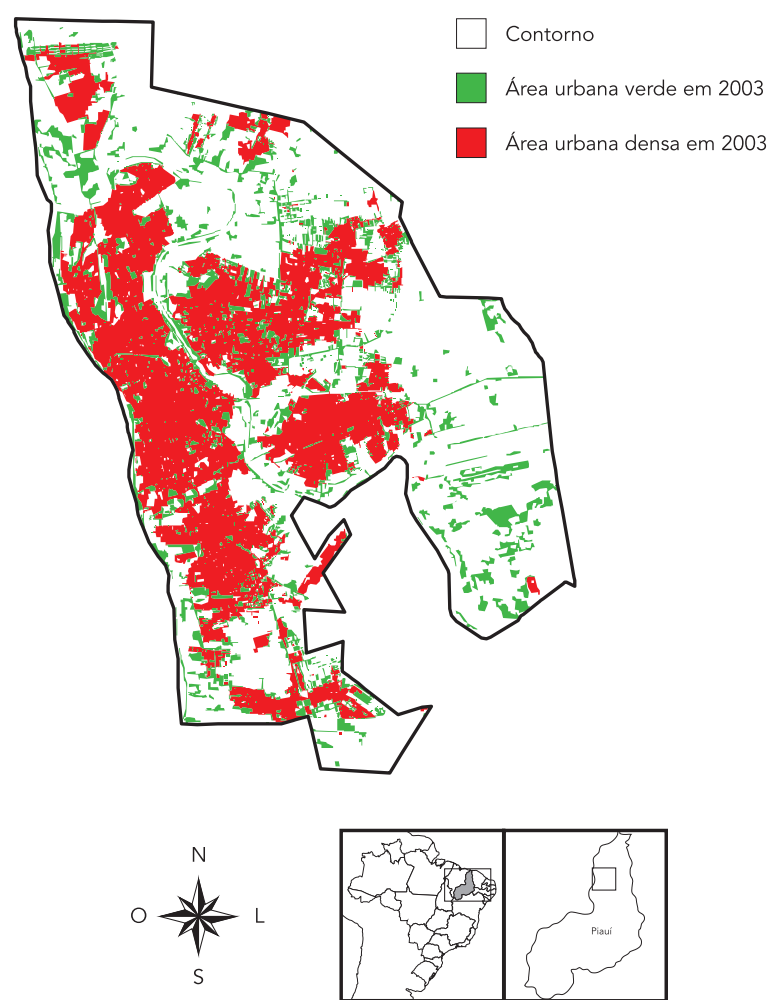
Figura 4

Mapa temático da expansão da área "Urbana densa" em 2003 para área "Urbana verde" em 1990 e com "Vegetação densa" em 1990. Teresina, Piauí, Brasil.

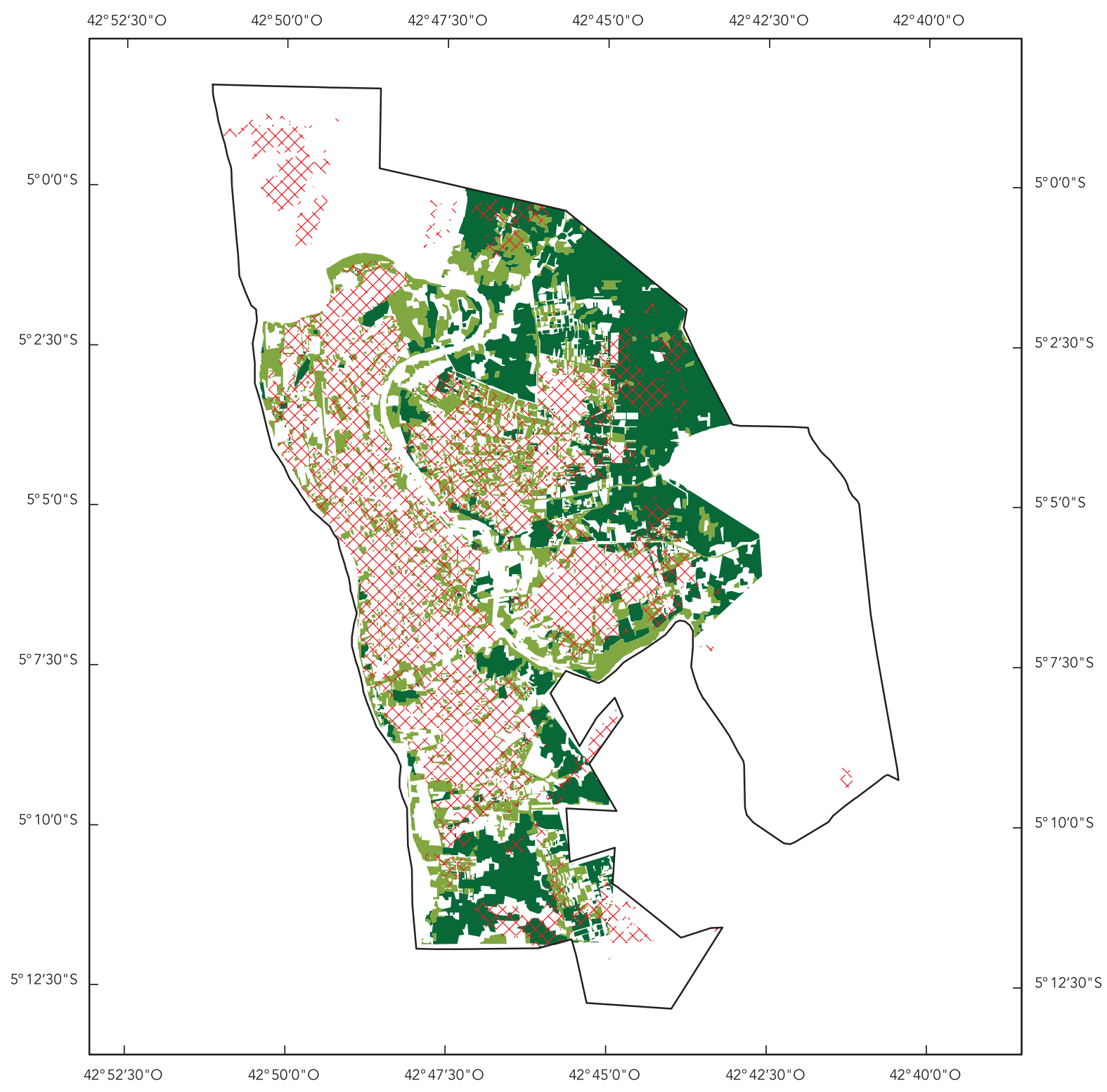

Contorno

Área urbana verde em 1990

Área com vegetação densa em 1990

Área urbana densa em 2003

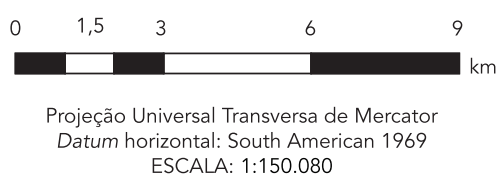

$0 \underbrace{N}_{S}$

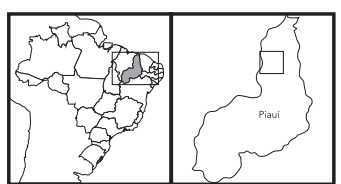


Matriz de correlação da incidência da leishmaniose visceral (LV) do período de 1993-1996 e de 2001-2006 e os indicadores ambientais extraídos da imagem de satélite Landsat 5 TM de 1990 e 2003, respectivamente (coeficiente de Spearman's). Teresina, Piauí, Brasil.

\begin{tabular}{|c|c|c|c|c|c|c|c|c|}
\hline & Incidência & Água & $\begin{array}{c}\text { Vegetação } \\
\text { densa }\end{array}$ & $\begin{array}{l}\text { Vegetação } \\
\text { rasteira }\end{array}$ & $\begin{array}{l}\text { Urbana } \\
\text { densa }\end{array}$ & $\begin{array}{l}\text { Urbana } \\
\text { verde }\end{array}$ & $\begin{array}{c}\text { Solo } \\
\text { exposto }\end{array}$ & $\begin{array}{c}\text { Tempera- } \\
\text { tura * }\end{array}$ \\
\hline \multicolumn{9}{|c|}{ Incidência de LV 1993-1996 e cena de 1990} \\
\hline Incidência & 1,00 & & & & & & & \\
\hline \multicolumn{9}{|l|}{ Valor de $p$} \\
\hline Água & $-0,102$ & 1,00 & & & & & & \\
\hline Valor de $\mathrm{p}$ & 0,035 & & & & & & & \\
\hline Vegetação densa & 0,236 & $-0,015$ & 1,00 & & & & & \\
\hline Valor de $\mathrm{p}$ & $<0,001$ & 0,754 & & & & & & \\
\hline Vegetação rasteira & 0,135 & 0,075 & 0,577 & 1,00 & & & & \\
\hline Valor de $\mathrm{p}$ & 0,005 & 0,119 & $<0,001$ & & & & & \\
\hline Urbana densa & $-0,118$ & $-0,012$ & 0,011 & 0,079 & 1,00 & & & \\
\hline Valor de $\mathrm{p}$ & 0,014 & 0,802 & 0,817 & 0,103 & & & & \\
\hline Urbana verde & $-0,016$ & $-0,083$ & $-0,344$ & $-0,414$ & $-0,774$ & 1,00 & & \\
\hline Valor de $p$ & 0,742 & 0,087 & $<0,001$ & $<0,001$ & $<0,001$ & & & \\
\hline Solo exposto & 0,113 & $-0,024$ & 0,276 & 0,267 & 0,018 & $-0,250$ & 1,00 & \\
\hline Valor de $p$ & 0,019 & 0,615 & $<0,001$ & $<0,001$ & 0,716 & $<0,001$ & & \\
\hline Temperatura * & $-0,117$ & $-0,094$ & $-0,474$ & $-0,509$ & $-0,207$ & 0,379 & $-0,089$ & 1,00 \\
\hline Valor de $p$ & 0,15 & 0,051 & $<0,001$ & $<0,001$ & $<0,001$ & $<0,001$ & 0,066 & \\
\hline \multicolumn{9}{|c|}{ Incidência de LV 2001-2006 e cena de 2003} \\
\hline Incidência & 1,00 & & & & & & & \\
\hline \multicolumn{9}{|l|}{ Valor de $p$} \\
\hline Água & $-0,024$ & 1,00 & & & & & & \\
\hline Valor de $\mathrm{p}$ & 0,538 & & & & & & & \\
\hline Vegetação densa & 0,174 & 0,085 & 1,00 & & & & & \\
\hline Valor de $\mathrm{p}$ & $<0,001$ & 0,029 & & & & & & \\
\hline Vegetação rasteira & 0,142 & 0,175 & 0,498 & 1,00 & & & & \\
\hline Valor de $\mathrm{p}$ & $<0,001$ & $<0,001$ & $<0,001$ & & & & & \\
\hline Urbana densa & 0,178 & $-0,084$ & 0,128 & 0,057 & 1,00 & & & \\
\hline Valor de $p$ & $<0,001$ & 0,033 & 0,001 & 0,147 & & & & \\
\hline Urbana verde & $-0,209$ & $-0,109$ & $-0,369$ & $-0,424$ & $-0,432$ & 1,00 & & \\
\hline Valor de $\mathrm{p}$ & $<0,001$ & 0,006 & $<0,001$ & $<0,001$ & $<0,001$ & & & \\
\hline Solo exposto & 0,142 & 0,038 & 0,272 & 0,274 & 0,009 & -0.657 & 1,00 & \\
\hline Valor de $p$ & $<0,001$ & 0,329 & $<0,001$ & $<0,001$ & 0,818 & $<0,001$ & & \\
\hline Temperatura * & $-0,194$ & $-0,241$ & $-0,539$ & $-0,630$ & $-0,248$ & 0,645 & $-0,435$ & 1,00 \\
\hline Valor de p & $<0,001$ & $<0,001$ & $<0,001$ & $<0,001$ & $<0,001$ & $<0,001$ & $<0,001$ & \\
\hline
\end{tabular}

* Temperatura média da superfície terrestre em cada setor censitário de Teresina.

Cabe ressaltar que os resultados obtidos neste estudo indicam que o método orientado a objeto produziu mapas de cobertura do solo urbano com boa acurácia temática para os períodos analisados. A acurácia temática refere-se à classificação adequada das classes na imagem segundo as classes que compõem a "verdade" terrestre ${ }^{24}$. Além disso, a classificação mostrou bom desempenho em termos de confiabilidade, conforme demonstrado pelos altos valores dos coeficientes kappa obtidos na classificação das duas imagens. Outro aspecto importante deste estudo foi a aplicação do mesmo conjunto de regras (descritores) às imagens de períodos distintos, ainda que tenha sido necessário calibrar os parâmetros usados na classificação, encontrando os valores de características e o grau de adesão a uma classe para a imagem de 2003 compatíveis com os encontrados para 1990. 
O uso de um mesmo procedimento em diferentes imagens permite alcançar maior potencial para a comparação temporal visando identificar modificações ambientais que podem estar relacionadas à ocorrência de doenças endêmicas. Ainda assim, os processos de segmentação e de descrição de classe têm de ser adaptados para cada imagem e estudo, mesmo que o fluxo de trabalho de classificação permaneça o mesmo 24 . Também, a rede proposta deve ser aperfeiçoada, inserindo-se novas classes temáticas e validando-a por meio de sua reaplicação em outras áreas.

A metodologia desenvolvida neste estudo para o mapeamento da cobertura do solo de Teresina, ao reunir as vantagens da análise orientada a objeto, como o uso de atributos de textura e de contexto, além de características espectrais, para segmentação e classificação, com aquelas fornecidas por imagens de média resolução espacial, como o baixo custo e disponibilidade para um amplo espectro temporal, facilita a utilização desse tipo de dado na área da saúde, particularmente para o mapeamento e monitoramento de áreas de grande extensão territorial. Segundo Alves et al. 12, o uso da classificação orientada a objetos tem um grande potencial para o mapeamento de áreas urbanizadas, não somente mediante o uso de imagens de alta resolução espacial, como já vem ocorrendo, mas também com as de média resolução.

Os resultados da correlação entre indicadores ambientais e incidência da LV em Teresina corroboram a adequação do processo de classificação das imagens na medida em que demonstram as já esperadas relações entre estrutura urbana e o contexto ambiental que favorecem a transmissão da LV em meio urbano. O indicador de área Urbana densa mostra que há um processo de expansão urbana em direção à periferia da cidade, local com maior cobertura vegetal. Essa situação tem criado cenários favoráveis para a reprodução do vetor L. longipalpis, já que esse se adapta facilmente às condições peridomiciliares, explorando o acúmulo de matéria orgânica gerada por animais domésticos e más condições sanitárias 5 . Além disso, alguns estudos apontam que domicílios localizados em regiões com maior cobertura vegetal e com elevada densidade populacional contribuem para altas taxas de incidência de LV. Isso significa que quanto maior for a proximidade com as florestas, maior também será o número de flebotomíneos nos domicílios, o que torna o risco de o indivíduo ser picado mais alto e, consequentemente, maior será a probabilidade de adquirir a infecção 25 .

Para observar as associações entre a doença e os indicadores ambientais neste estudo, foi utilizada a menor unidade territorial de coleta das operações censitárias do Instituto Brasileiro de Geografia e Estatística (IBGE). Entretanto, cabe mencionar que essas unidades territoriais na cidade de Teresina apresentam dimensões físicas distintas, o que pode ter levado à baixa homogeneidade interna em relação a alguns indicadores analisados. Essa situação pode ter ocorrido porque cada setor censitário corresponde à capacidade de levantamento do recenseador em relação aos domicílios. Quintana et al. ${ }^{26}$, usando diferentes escalas de análise para avaliar a distribuição e abundância espacial e temporal dos vetores da leishmaniose tegumentar e da LV na Argentina, concluíram que níveis variados de escalas geram informações que contribuem para desenhar estratégias de prevenção e controle das leishmanioses, embora destaquem a necessidade de resolução, qualidade dos dados e diferentes formas de análise para suportar as conclusões adequadas em cada escala. Rosa-Freitas et al. 27 apontam vários trabalhos que investigam diferentes escalas espaciais e temporais com o propósito de aumentar a compreensão sobre epidemiologia de doenças transmitidas por vetores, bem como apoiar as decisões nos programas de controle.

A temperatura média da superfície terrestre da cidade apresentou correlação negativa com a incidência de LV nos dois períodos analisados. Em princípio, esperava-se uma correlação positiva, considerando que temperaturas mais altas poderiam favorecer maiores densidades do vetor que, por sua vez, estão correlacionadas com a ocorrência de casos humanos 28. Entretanto, estudos realizados no Brasil geraram resultados inconsistentes sobre a relação entre temperatura e abundância de L. longipalpis. Há estudos encontrando relação direta 29 , relação inversa 30 ausência de associação 31,32 e mesmo relações direta e inversa em diferentes sítios amostrais num mesmo município ${ }^{33}$. Dentre os diversos possíveis motivos para tais discrepâncias destacam-se a dependência de flebotomíneos de outras variáveis climáticas, como umidade, que, por sua vez, também pode se correlacionar com temperatura, diferenças nos microambientes estudados e no tipo de método estatístico utilizado para analisar os dados 28 . Ximenes et al. 28, por exemplo, empregando modelos de séries temporais, encontraram correlação positiva significativa entre temperatura e densidade de fêmeas de L. longipalpis para uma janela temporal de três meses, isto é, o aumento de flebotomíneos ocorreu três meses após o pico de temperatura 28 . Nesse caso, uma análise seccional (temperatura e abundância de vetores mensuradas no mesmo momento) levaria a uma correlação negativa entre essas variáveis. Neste 
estudo, além da ausência de um componente temporal e de dados sobre vetores, o que limita a interpretação dessas correlações, há ainda a pequena variação de temperatura média nos setores censitários no período analisado, indicando que as condições térmicas foram relativamente constantes na cidade. De fato, as médias (desvios-padrão) da temperatura nos setores censitários foram de 31,99 (0,96), em 1990, e de 29,1 (1,22), em 2003. Assim, a pequena variabilidade da temperatura na cidade sugere que outros fatores, como aqueles ligados a questões sociais, ambientais e do próprio indivíduo, teriam maior participação na ocorrência da doença em Teresina.

Tanto os aspectos sociais como os ambientais devem ser levados em conta nas análises de doenças infecciosas, em especial a LV, uma vez que as interações saúde-ambiente são sempre mediadas por vários fatores, e essa mediação é a chave para a compreensão dos mecanismos e resultados dessas interações. Nessa perspectiva, a incorporação de uma visão mais ampla do conjunto de fatores ambientais, decorrentes da atividade humana ou da natureza, deve fazer parte do monitoramento das doenças infecciosas, levando-se, em consideração, o território onde as interações entre o homem e o meio ambiente ocorrem. Pode-se dizer que o entendimento das interações saúde-ambiente constitui-se como um pré-requisito para o desenvolvimento de pesquisas em LV. Barcellos et al. 34 reforçam a relevância dos múltiplos fatores (ambientais, sociais, biológicos, médico-sociais, entre outros) que influenciam a dinâmica das doenças transmitidas por vetores, além do importante papel das mudanças climáticas na expansão das áreas de incidência dessas doenças.

Estudos realizados com imagens de média resolução espacial e métodos tradicionais de classificação foram capazes de identificar alguns elementos relativos à cobertura vegetal, ao uso do solo e a padrões de ocupação urbana associados ao risco de LV 25,30,35,36,37. Contudo, a aplicação da classificação orientada a objeto às imagens de média resolução espacial pode apresentar vantagens potenciais em relação a esses métodos, como uma maior reprodutibilidade, flexibilidade $\mathrm{e}$ utilização de informações contextuais para além das espectrais 9 .
Estudos que comparam a aplicação da classificação orientada a objeto com métodos tradicionais de classificação mostraram que a classificação orientada a objeto apresentou maior capacidade na separação dos alvos 38,39. Segundo Desclée et al. 38, a acurácia na detecção de mudanças na cobertura florestal foi maior com a classificação orientada a objetos do que a obtida pela classificação com base em pixels 38 . Também Fernandes et al. ${ }^{39}$, ao comparar a classificação orientada a objetos com o classificador pixel a pixel no mapeamento de áreas degradadas no Estado do Mato Grosso, observaram melhores resultados finais para detectar áreas de cobertura vegetal alterada com a classificação orientada a objetos.

Ressalta-se que a estruturação da rede hierárquica de classes temáticas é importante no processo de classificação de imagens, já que, por meio dela, é possível estabelecer relações entre objetos de níveis distintos, facilitando a separação de classes. Além disso, as informações temáticas auxiliam no processo de segmentação e classificação. Dessa forma, o uso de informações vetoriais no processo de segmentação das imagens pode, em alguns casos, auxiliar na definição do limite dos objetos, especialmente quando utilizamos uma malha digital de logradouros/ruas.

São grandes os desafios conceituais e analíticos relacionados à utilização de imagens de satélite em estudos epidemiológicos sobre doenças transmitidas por vetores, em particular a LV em meio urbano. Há também dificuldades práticas, já que exige não só a obtenção de dados de campo sobre LV e características do uso do solo e cobertura vegetal, mas também a aplicação de técnicas complexas para o processamento dessas imagens de forma a se obter informações relevantes para o estudo da temática em questão.

Existem ainda muitas incertezas sobre a potencial utilidade do sensoriamento remoto como ferramenta auxiliar nas investigações sobre os fatores relacionados aos padrões de ocorrência e disseminação de doenças e, também, nas ações de vigilância e controle. Nesse sentido, este trabalho busca apontar caminhos e possibilidades de desenvolvimento na área de classificação de imagens de forma a contribuir para uma melhor compreensão dos mecanismos relacionados à ocorrência da LV em meio urbano. 


\section{Resumen}

Este estudio investigó el uso de la clasificación orientada a objetos de imágenes satélite en estudios epidemiológicos acerca de la leishmaniasis visceral (LV) en zonas urbanas. Se aplicó la clasificación orientada a objetos en escenas Landsat 5 TM de la ciudad de Teresina, Piauí, Brasil, para obtener información ambiental y temperatura. De 1993 a 1996, la tasa de incidencia de LV en los sectores censales de la ciudad se correlacionó positivamente con el área del sector censal cubierto por vegetación densa, pastos y suelo desnudo, y negativamente con el área cubierta por agua y zonas densamente pobladas. De 2001 a 2006 se han encontrado correlaciones positivas con vegetación densa, vegetación tipo maleza, suelo desnudo y zonas densamente pobladas, y negativas con áreas urbanas con poca vegetación. La temperatura se asoció negativamente con la incidencia de la LV en ambos períodos. La clasificación orientada a objetos puede ser útil para caracterizar los paisajes asociados a la ocurrencia de la LV en áreas urbanas y delimitar zonas de riesgo para establecer prioridades de intervención.

Tecnología de Sensores Remotos; Imágenes Satelitales; Leishmaniasis Visceral

\section{Referências}

1. Saraiva MGG, Amorim RDS, Moura MAS, MartinezEspinosa FE, Barbosa MGV. Expansão urbana e distribuição espacial da malária no Município de Manaus, Estado do Amazonas. Rev Soc Bras Med Trop 2009; 42:515-22.

2. Kawa H, Sabroza PC, Oliveira RM, Barcellos C. A produção do lugar de transmissão da leishmaniose tegumentar: o caso da Localidade Pau da Fome na cidade do Rio de Janeiro, Brasil. Cad Saúde Pública 2010; 26:1495-507.

3. Correia VRM, Carvalho MS, Sabroza PC, Vasconcelos $\mathrm{CH}$. Remote sensing as a tool to survey endemic diseases in Brazil. Cad Saúde Pública 2004; 20:891-904.

4. Hugh-Jones M. Applications of remote sensing to the identification of the habitats of parasites and disease vectors. Parasitol Today 1989; 5:244-51.

5. Rangel EF, Vilela ML. Lutzomyia longipalpis (Diptera, Psychodidae, Phlebotominae) and urbanization of visceral leishmaniasis in Brazil. Cad Saúde Pública 2008; 24:2948-52.

\section{Colaboradores}

A. S. Almeida e G. L. Werneck participaram da concepção, planejamento, análise e interpretação dos dados, revisão crítica do conteúdo e aprovação da versão final do manuscrito. A. P. C. Resendes participou da análise e interpretação dos dados, revisão crítica do conteúdo e aprovação da versão final do manuscrito.

\section{Agradecimentos}

Os autores agradecem ao pesquisador Paulo Chagastelles Sabroza (Ensp/Fiocruz) por ter, gentilmente, permitido a utilização da infraestrutura para realização da classificação das imagens de satélite utilizadas neste artigo. A pesquisa, neste trabalho, foi financiada pelo CNPq (processos 160571/2011-1, 202088/2012-0 e 306267/2010-1).
6. Werneck GL. Geographic spread of visceral leish maniasis in Brazil. Cad Saúde Pública 2010; 26:644-5.

7. Alves CD, Florenzano TG, Pereira MN. Mapeamento de áreas urbanizadas com imagens Landsat e classificação baseada em objeto. Revista Brasileira de Cartografia 2010; (62/2):189-98.

8. Hay G J, Castilla G. Object-based image analysis: Strengths, Weaknesses, Opportunities and Threats (SWOT). International Archives of Photogrammetry, Remote Sensing and Spatial Information Sciences 2006; v. XXXVI-4/C42.

9. Blaschke T. Object based image analysis for remote sensing. ISPRS J Photogramm 2010; 65:2-16.

10. Costa CHN, Pereira HF, Araújo MV. Epidemia de leishmaniose visceral no Estado do Piauí, Brasil 1980-1986. Rev Saúde Pública 1990; 24:361-72.

11. Shryock HS, Siegel JS. The methods and materials of demography. San Diego: Academic Press; 1976. 
12. Alves CD, Pereira MN, Florenzano TG, Souza IM. Análise orientada a objeto no mapeamento de áreas urbanas com imagens Landsat. Bol Ciênc Geod 2009; 15:120-41.

13. Baatz, M, Schäpe A. Multiresolution segmentation - an optimization approach for high quality multiscale image segmentation. In: Strobl J, Blaschke T, editors. Angewandte Geographische Informations verarbeitung XII. Beiträge zum AGITSymposium Salzburg. Karlsruhe: Herbert Wichmann Verlag; 2000. p. 12-23.

14. Knight JF, Lunetta RS. An experimental assessment of minimum mapping unit size. IEEE T Geosci Remote 2003 ; 41:2132-4.

15. Zha Y, Gao J, Ni S. Use of normalized difference build-up index in automatically mapping urban areas from TM imagery. Int J Remote Sens 2003; 24:583-94

16. Jensen JR. Introductory digital image processing: a remote sensing perspective. 2nd Ed. Upper Saddle River: Prentice Hall; 1996.

17. Congalton R, Green K. Assessing the accuracy of remotely sensed data: principles and practices. Boca Raton: CRC/Lewis Press; 1999.

18. Szklo M, Javier Nieto F. Epidemiology: beyond the basics. 3rd Ed. Burlington: Jones \& Bartlett; 2014.

19. Malaret E, Bartolucci LA, Lozano DF, Anuta PE, McGillen CD. LANDSAT- 4 and LANDSAT- 5 thematic mapper data quality analysis. Photogramm Eng Remote Sensing 1985; 51:1407-16.

20. Reichenheim ME, Moraes CL. Operacionalização de adaptação transcultural de instrumentos de aferição usados em epidemiologia. Rev Saúde Pública 2007; 41:665-73.

21. Chubey MS, Franklin E, Wulder MA. Object- based analysis of Ikonos-2 imagery for extraction of forest inventory parameters. Photogramm Eng Remote Sensing 2006; 72:383-94.

22. Jacquin A, Misakova L, Gay M. A hybrid objectbased classification approach for mapping urban sprawl in periurban environment. Landsc Urban Plan 2008; 84:152-65.

23. Tönjes R, Growe S, Bückner J, Liedtke CE. Knowledge-based interpretation of remote sensing images using semantic nets. Photogramm Eng Remote Sensing 1999; 65:811-21.

24. Bolfe EL, Pereira RS, Madruga PRA, Fonseca EL. Avaliação da classificação digital de povoamentos florestais em imagens de satélite através de índices de acurácia. Rev Ârvore 2004; 28:85-90.

25. Werneck GL, Maguire JH. Spatial modeling using mixed models: an ecologic study of visceral leishmaniasis in Teresina, Piauí State, Brazil. Cad Saúde Pública 2002; 18:633-7.

26. Quintana MG, Fernández MS, Salomón OD. Distribution and abundance of phlebotominae, vectors of leishmaniasis, in Argentina: spatial and temporal analysis at different scales. J Trop Med 2012; 2012:652803.

27. Rosa-Freitas MG, Honório NA, Codeço CT, Werneck GL, Degallier N. Spatial studies on vectortransmitted diseases and vectors. J Trop Med 2012; 2012:573965.
28. Ximenes MF, Castellón EG, De Souza MF, Menezes AA, Queiroz JW, Macedo e Silva VP, et al. Effect of abiotic factors on seasonal population dynamics of Lutzomyia longipalpis (Diptera: Psychodidae) in northeastern Brazil. J Med Entomol 2006; 43:990-5.

29. Michalsky EM, Fortes-Dias CL, França-Silva JC, Rocha MF, Barata RA, Dias ES. Association of $L u$ tzomyia longipalpis (Diptera: Psychodidae) population density with climate variables in Montes Claros, an area of American visceral leishmaniasis transmission in the state of Minas Gerais, Brazil. Mem Inst Oswaldo Cruz 2009; 104:1191-3.

30. Amóra SS, Bevilaqua CM, Feijó FM, Oliveira PG, Peixoto GC, Sousa RN, et al. Sandflies (Psychodidae: Phlebotominae) survey in an urban transmission area of visceral leishmaniasis, Northeastern Brazil. Rev Bras Parasitol Vet 2010; 19:233-7.

31. Costa PL, Dantas-Torres F, da Silva FJ, Guimarães VC, Gaudêncio K, Brandão-Filho SP. Ecology of Lutzomyia longipalpis in an area of visceral leishmaniasis transmission in north-eastern Brazil. Acta Trop 2013; 126:99-102.

32. Queiroz MF, Varjão JR, Moraes SC, Salcedo GE. Analysis of sandflies (Diptera: Psychodidae) in Barra do Garças, State of Mato Grosso, Brazil, and the influence of environmental variables on the vector density of Lutzomyia longipalpis (Lutz \& Neiva, 1912). Rev Soc Bras Med Trop 2012; 45:313-7.

33. Oliveira AG, Galati EA, Fernandes CE, Dorval ME, Brazil RP. Seasonal variation of Lutzomyia longipalpis (Lutz \& Neiva, 1912) (Diptera: Psychodidae: Phlebotominae) in endemic area of visceral leishmaniasis, Campo Grande, state of Mato Grosso do Sul, Brazil. Acta Trop 2008; 105:55-61.

34. Barcellos C, Monteiro AMV, Corvalán C, Gurgel HC, Carvalho MS, Artaxo P, et al. Mudanças climáticas e ambientais e as doenças infecciosas: cenários e incertezas para o Brasil. Epidemiol Serv Saúde 2009; 18:285-304.

35. Correia VRM, Monteiro AM, Carvalho MS, Werneck GL. Uma aplicação do sensoriamento remoto para a investigação de endemias urbanas. Cad Saúde Pública 2007; 23:1015-28.

36. Cerbino Neto J, Werneck GL, Costa CHN. Factors associated with the incidence of urban visceral leishmaniasis: an ecological study in Teresina, Piauí State, Brazil. Cad Saúde Pública 2009; 25:1543-51.

37. Werneck GL, Costa CHN, Walker AM, David JR, Wand M, Maguire JH. Multilevel modelling of the incidence of visceral leishmaniasis in Teresina, Brazil. Epidemiol Infect 2007; 135:195-201.

38. Desclée B, Bogaert P, Defourny P. Forest change detection by statistical object-based method. Remote Sens Environ 2006; 102:1-11.

39. Fernandes RR, Nunes GM, Drescher R. Monitoramento de propriedades rurais através de dados multisensores em nível orbital. Ambiência 2011; 7:75-87.

Recebido em 21/Mar/2013

Versão final reapresentada em 27/Set/2013

Aprovado em 30/Jan/2014 